\title{
Myristyltrimethylammonium Bromide (MYTAB) as a Cationic Surface Agent to Inhibit Streptococcus mutans Grown over Dental Resins: An In Vitro Study
}

\author{
Paola Andrea Mena Silva ${ }^{1,2,3}$, Isadora Martini Garcia ${ }^{1}$, Julia Nunes ${ }^{4}$, Fernanda Visioli ${ }^{4} \mathbb{D}_{\text {, }}$ \\ Vicente Castelo Branco Leitune ${ }^{1}\left(\mathbb{D}\right.$, Mary Anne Melo ${ }^{5,6, *(1)}$ and Fabrício Mezzomo Collares $1, *(\mathbb{B})$ \\ 1 Dental Materials Laboratory, School of Dentistry, Federal University of Rio Grande do Sul, 90035-003 Porto \\ Alegre-RS, Brazil; pao_mena100@hotmail.com (P.A.M.S.); isadora.garcia@ufrgs.br (I.M.G.); \\ vicente.leitune@ufrgs.br (V.C.B.L.) \\ 2 Universidad Central del Ecuador, 170129 Quito, Ecuador \\ 3 Postgraduate Department, Universidad Regional Autónoma de Los Andes, 170129 Quito, Ecuador \\ 4 Oral Pathology Department, School of Dentistry, Federal University of Rio Grande do Sul, 90035-003 Porto \\ Alegre-RS, Brazil; jusnunes@icloud.com (J.N.); fernanda.visioli@ufrgs.br (F.V.) \\ 5 Operative Dentistry Division, General Dentistry Department, University of Maryland School of Dentistry, \\ Baltimore, MD 21201, USA \\ 6 Ph.D. Program in Biomedical Sciences, University of Maryland School of Dentistry, Baltimore, \\ MD 21201, USA \\ * Correspondence: mmelo@umaryland.edu (M.A.M.); fabricio.collares@ufrgs.br (F.M.C.)
}

Received: 16 January 2020; Accepted: 11 February 2020; Published: 15 February 2020

\begin{abstract}
This in vitro study evaluated the effect of myristyltrimethylammonium bromide (MYTAB) on the physical, chemical, and biological properties of an experimental dental resin. The resin was formulated with dental dimetacrylate monomers and a photoinitiator/co-initiator system. MYTAB was added at $0.5\left(\mathrm{G}_{0.5 \%}\right), 1\left(\mathrm{G}_{1} \%\right)$, and $2\left(\mathrm{G}_{2} \%\right)$ wt $\%$, and one group remained without MYTAB and was used as the control $\left(\mathrm{G}_{\mathrm{Ctrl}}\right)$. The resins were analyzed for the polymerization kinetics, degree of conversion, ultimate tensile strength (UTS), antibacterial activity against Streptococcus mutans, and cytotoxicity against human keratinocytes. Changes in the polymerization kinetics profiling were observed, and the degree of conversion ranged from $57.36 \%( \pm 2.50 \%)$ for $\mathrm{G}_{2} \%$ to $61.88 \%( \pm 1.91 \%)$ for $\mathrm{G}_{0.5 \%}$, without a statistically significant difference among groups $(p>0.05)$. The UTS values ranged from $32.85( \pm 6.08) \mathrm{MPa}$ for $\mathrm{G}_{0.5 \%}$ to $35.12( \pm 5.74) \mathrm{MPa}$ for $\mathrm{G}_{\mathrm{Ctrl}}(p>0.05)$. MYTAB groups showed antibacterial activity against biofilm formation from $0.5 \mathrm{wt} \%(p<0.05)$ and against planktonic bacteria from $1 \mathrm{wt} \%(p<0.05)$. The higher the MYTAB concentration, the higher the cytotoxic effect, without differences between $\mathrm{G}_{\mathrm{Ctrl}} \mathrm{e} \mathrm{G}_{0.5 \%}(p>0.05)$. In conclusion, the addition of $0.5 \mathrm{wt} \%$ of MYTAB did not alter the physical and chemical properties of the dental resin and provided antibacterial activity without cytotoxic effect.
\end{abstract}

Keywords: dental materials; dentistry; anti-bacterial agents; dental caries; biocompatible materials; biofilms; quaternary ammonium compounds

\section{Introduction}

Dental caries-linked bacteria growing in biofilms play a pivotal role in the initial formation and development of carious lesions. The demand for the development of antibacterial surfaces has gained prominence in order to reduce patients' susceptibility to new or repeated diseases [1-5]. In dentistry, dental materials have been developed with antibacterial agents to provide new preventive and treatment dynamics for patients [6-9]. The antibacterial approach for dental materials relies on 
biological interactions of the bacteria grown over the materials, and the contact with antibacterial agents presents in the surface or is released by the materials [10-13]. In this context, the achievement of surfaces able to reduce caries-linked biofilm formation over dental tissues or restorative structures has gained the attention of dental biomaterial researchers.

The current understanding of the dental caries disease process and the new advances in dental materials promote the preservation of dental structure and the application of minimally invasive techniques [14]. Under this framework, dental resins are the first option for the replacement of dental hard tissues that were lost due to carious lesions $[15,16]$. Dental resins are materials cured by chemical or physicochemical (via photo-activation) processes, and they present inorganic fillers depending on their purpose. In areas where it is necessary to increase strength (occlusal/chewing surfaces of teeth), a high amount of inorganic fillers is incorporated [17]. Dental resins with low viscosity can also be successfully used to seal the biting surfaces of teeth, decreasing the incidence of caries lesions [18].

The oral environment provides many challenges to the physical and chemical stability of dental resins, such as high humidity, temperature, and $\mathrm{pH}$ variations $[19,20]$. Likewise, acids leached by high acidogenic caries-linked bacteria such as Streptococcus mutans, conjointly with a degradative attack of enzymes, inherently present in the saliva, can jeopardize the materials' properties over time [21]. More expressively, acidic attack from high acidogenic caries-linked bacteria is a crucial step in tooth demineralization around the restorations [22]. On this basis, the search for long-lasting strategies challenging biofilm accumulation on dental resins, as well as the consequent caries lesion development around restorations, must be addressed.

Antibacterial surfaces with a bacteria-killing function have shown great promise in biological and biomedical applications, in particular for dental resin-based materials. This approach employs the incorporation of quaternary ammonium compounds (QACs) in the monomeric blend of the resin-based material formulation $[9,11,23]$. QACs have facile synthesis, antibacterial property, and a lack of a detrimental effect on the mechanical and physical properties when incorporated in concentrations. Typically, QAS exhibits a positive charge, which confers the surface with the ability to attach and kill bacteria efficiently. The killing effect is attributed to their electronically interaction and linking to bacteria membrane and wall, along with their possible diffusion into the cytoplasmic membrane, an increase of osmotic pressure, and the release of some cytoplasmic constituents [24,25].

Myristyltrimethylammonium bromide (MYTAB) is a QAC with an alkyl-chain length of 14 carbons presenting a chemical structure of $\mathrm{C}_{17} \mathrm{H}_{38} \mathrm{NBr}$, a molecular weight of 336.39 , and a cationic polar head group. Trimethyl alkylammonium compounds such as the MYTAB series can also strongly affect bacterial membrane properties of a wide range of microorganisms, including changes in electrokinetic potential as well as net surface charge [26]. A recent study has shown promising application for the sealing of dental roots during endodontic treatment with expressive bacterial reduction of the endodontic pathogen [27]. Additionally, the long-chain MYTAB presents the potential to act as a useful endocytosis inhibitor for cell biology, inhibiting different forms of endocytosis in multiple cell systems [26].

The present study aimed to evaluate the potential ability of MYTAB to impair bacterial reduction when incorporated into dental resin at increasing concentrations. Its antibacterial effects against S. mutans, a pivotal cariogenic pathogen presented in planktonic and biofilm stages, were assessed. The cytotoxicity effect on human keratinocytes was investigated. The chemical and physical effects of its incorporation on the materials were also explored.

\section{Results}

Figure 1 shows the results of polymerization kinetics (Figure 1a-c), degree of conversion (Figure 1d), and ultimate tensile strength (UTS) (Figure 1e). The experimental dental resins had different polymerization behavior throughout the $40 \mathrm{~s}$ of photoactivation. The degree of conversion per time is shown in Figure 1a. The results (Figure 2d) ranged from $57.36 \%( \pm 2.50 \%)$ for $\mathrm{G}_{2} \%$ to $61.88 \%$ $( \pm 1.91 \%)$ for $\mathrm{G}_{0.5 \%}$, without statistical difference among groups $(p>0.05)$. Figure $1 \mathrm{~b}$ indicates the results 
of the polymerization rate per time, showing that the higher the concentration of MYTAB, the higher the delay in achieving the maximum polymerization rate. Moreover, the higher the concentration of MYTAB, the lower the maximum polymerization rate. Figure $1 \mathrm{c}$ displays these differences, showing that at the same degree of conversion among groups, the polymerization rate of $\mathrm{G}_{\mathrm{Ctrl}}$ was higher than $\mathrm{G}_{1 \%}$ and $\mathrm{G}_{2 \%}$ and lower than $\mathrm{G}_{0.5 \%}$. In Figure $1 \mathrm{~d}$, the degree of conversion revealed similar behavior for the tested groups $(p>0.05)$. The mechanical property of the dental resins was evaluated under UTS and expressed in $\mathrm{MPa}$, as shown in Figure 1e. The UTS ranged from $32.85( \pm 6.08) \mathrm{MPa}$ for $\mathrm{G}_{0.5 \%}$ to $35.12( \pm 5.74) \mathrm{MPa}$ for $\mathrm{G}_{\mathrm{Ctrl}}$. There was no statistical difference among groups $(p>0.05)$.
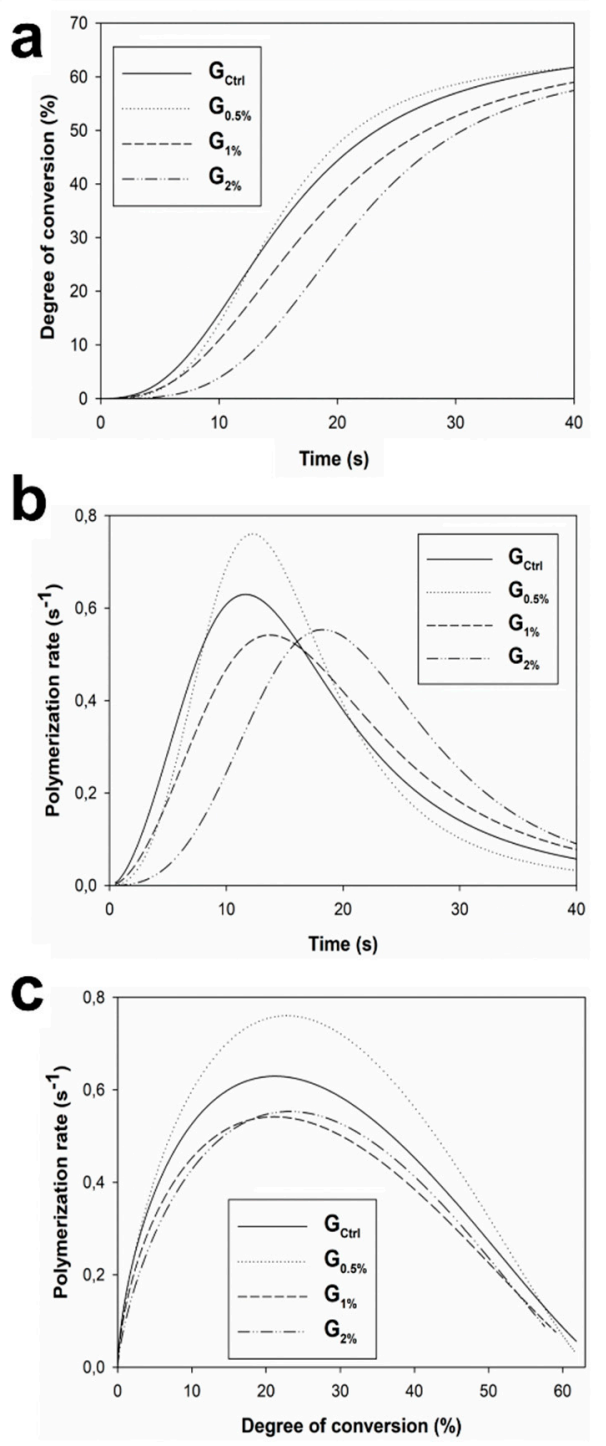

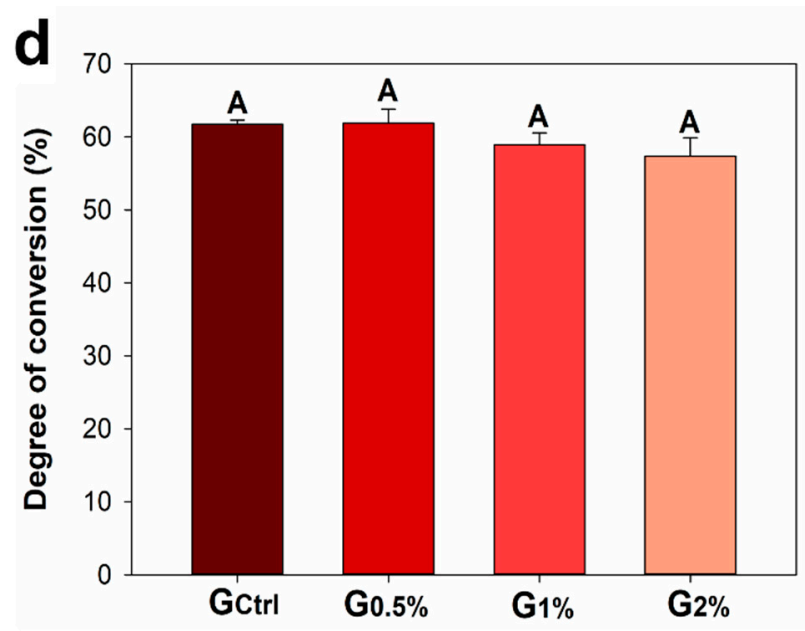

e

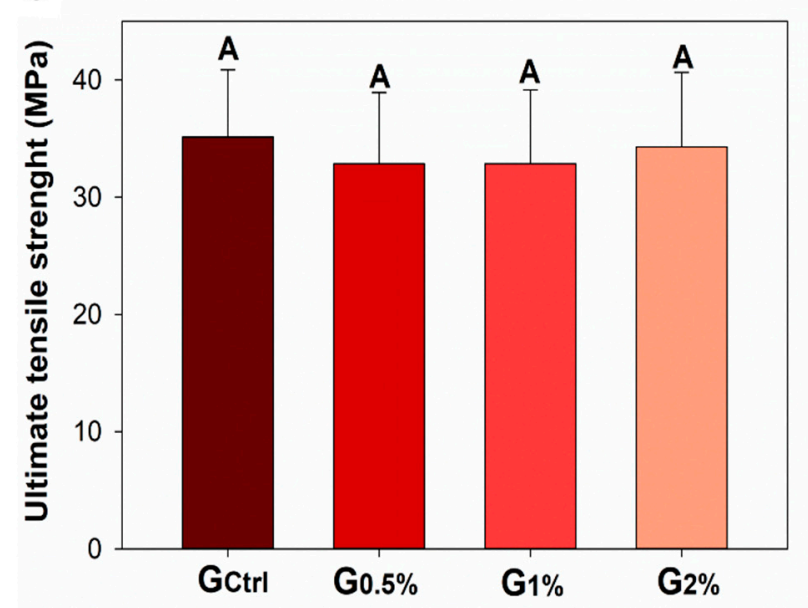

Figure 1. Comprehensive results of polymerization kinetics $(\mathbf{a}-\mathbf{c})$, degree of conversion after $40 \mathrm{~s}$ of photoactivation (d), and ultimate tensile strength (UTS) (e). Same capital letters indicate no statistical difference among groups $(p>0.05)$. The groups had different polymerization kinetics without statistical difference for the degree of conversion and UTS.

Figure 2 shows the results of the antibacterial activity of the experimental dental resins against biofilm formation of $S$. mutans and planktonic $S$. mutans, expressed by the log reduction in colony-forming unit per milliliter. In the microbiological assessment against biofilm formation (Figure 2a), the values ranged from $4.58( \pm 0.08) \log \mathrm{CFU} / \mathrm{mL}$ for $\mathrm{G}_{2} \%$ to $7.21( \pm 0.08) \log \mathrm{CFU} / \mathrm{mL}$ for $\mathrm{G}_{\mathrm{Ctrl}}(p<0.05)$. A greater bacterial reduction $(p<0.05)$ was observed at the higher concentration of MYTAB incorporated into the dental resin. In the test against planktonic bacteria (Figure $2 b$ ), the values 
ranged from $6.68( \pm 0.58) \log \mathrm{CFU} / \mathrm{mL}$ for $\mathrm{G}_{2 \%}$ to $8.28( \pm 0.05) \log \mathrm{CFU} / \mathrm{mL}$ for $\mathrm{G}_{\mathrm{Ctrl}}(p<0.05)$. The group presenting MYTAB concentration at $2 \%$ expressed the highest $S$. mutans bacterial reduction $(p<0.05)$.
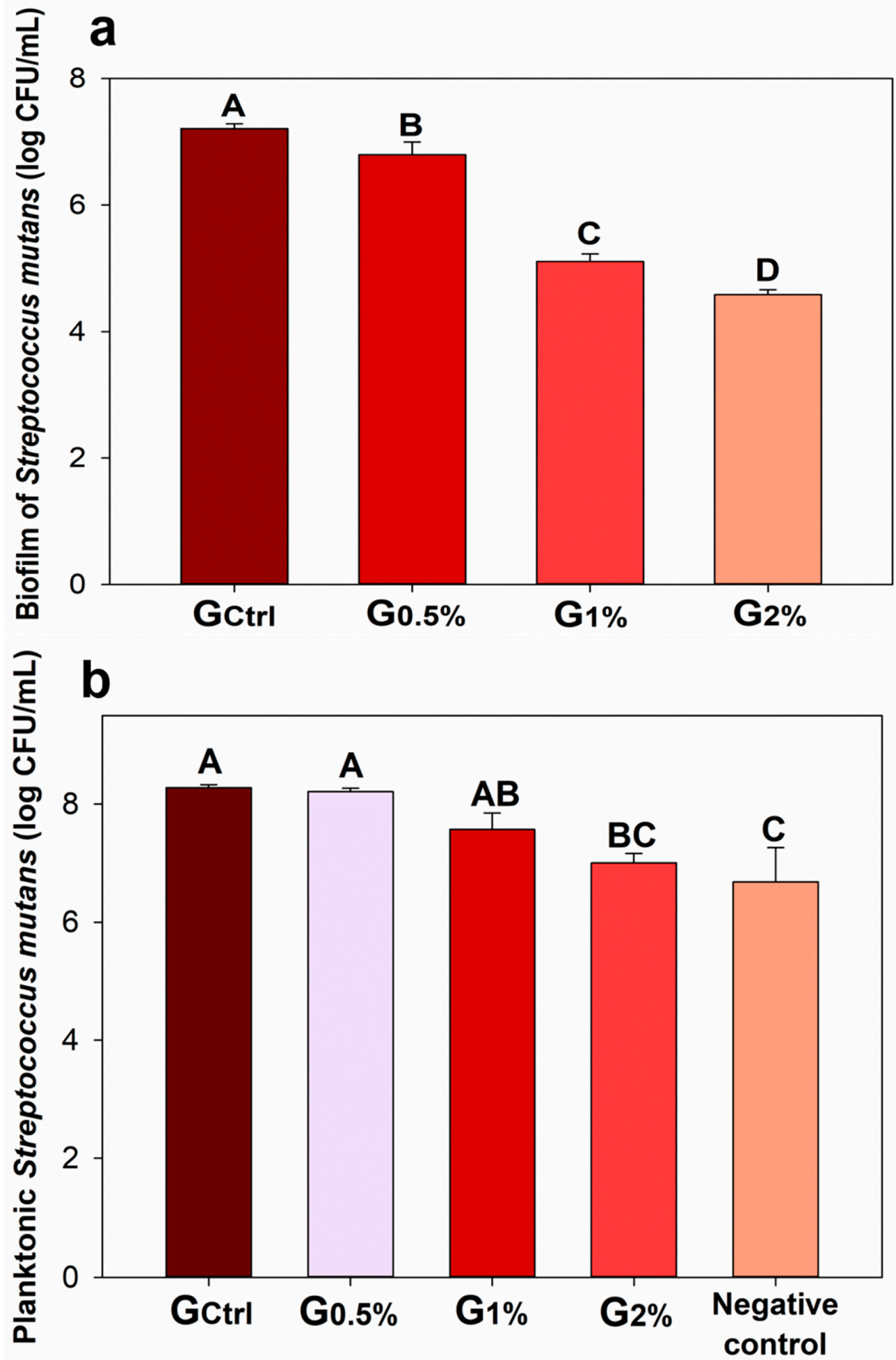

Figure 2. Bacterial colony forming unit counting: (a) Streptococcus mutans biofilms and (b) planktonic $S$. mutans that were in contact with the polymerized samples. Values indicated by different letters indicate statistical differences among the groups $(p<0.05)$. 
Figure 3 presents the effects of MYTAB incorporated into a dental resin on normal human keratinocytes (HaCaT) for cytotoxicity assessed by sulforhodamine B (SRB) assay. The percentage of viability of the cells ranged from $45.26 \%( \pm 14.11 \%)$ for $\mathrm{G}_{2 \%}$ to $110.16 \%( \pm 14.64 \%)$ for $\mathrm{G}_{\mathrm{Ctrl}}(p<0.05)$. $\mathrm{G}_{0.5 \%}(91.82 \% \pm 12.17 \%)$ presented no statistical difference in comparison to $\mathrm{G}_{\mathrm{Ctrl}}(p>0.05)$ for cytotoxicity against human keratinocytes.

\section{a}

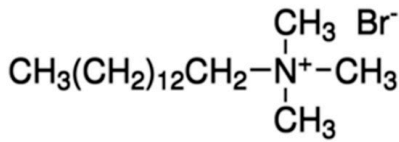

$\operatorname{MYTAB}\left(\mathrm{C}_{14}\right)$

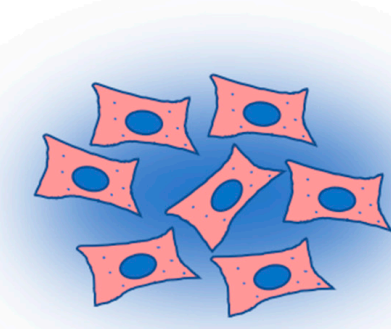

Viable human

keratinocytes $(\mathrm{HaCaT})$

b
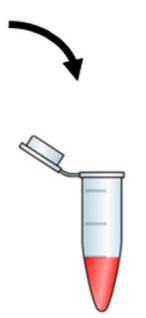

1

Washing
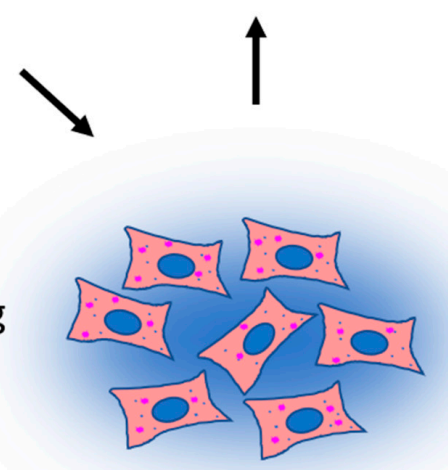

Staining of cellular proteins

by Sulforhodamine B

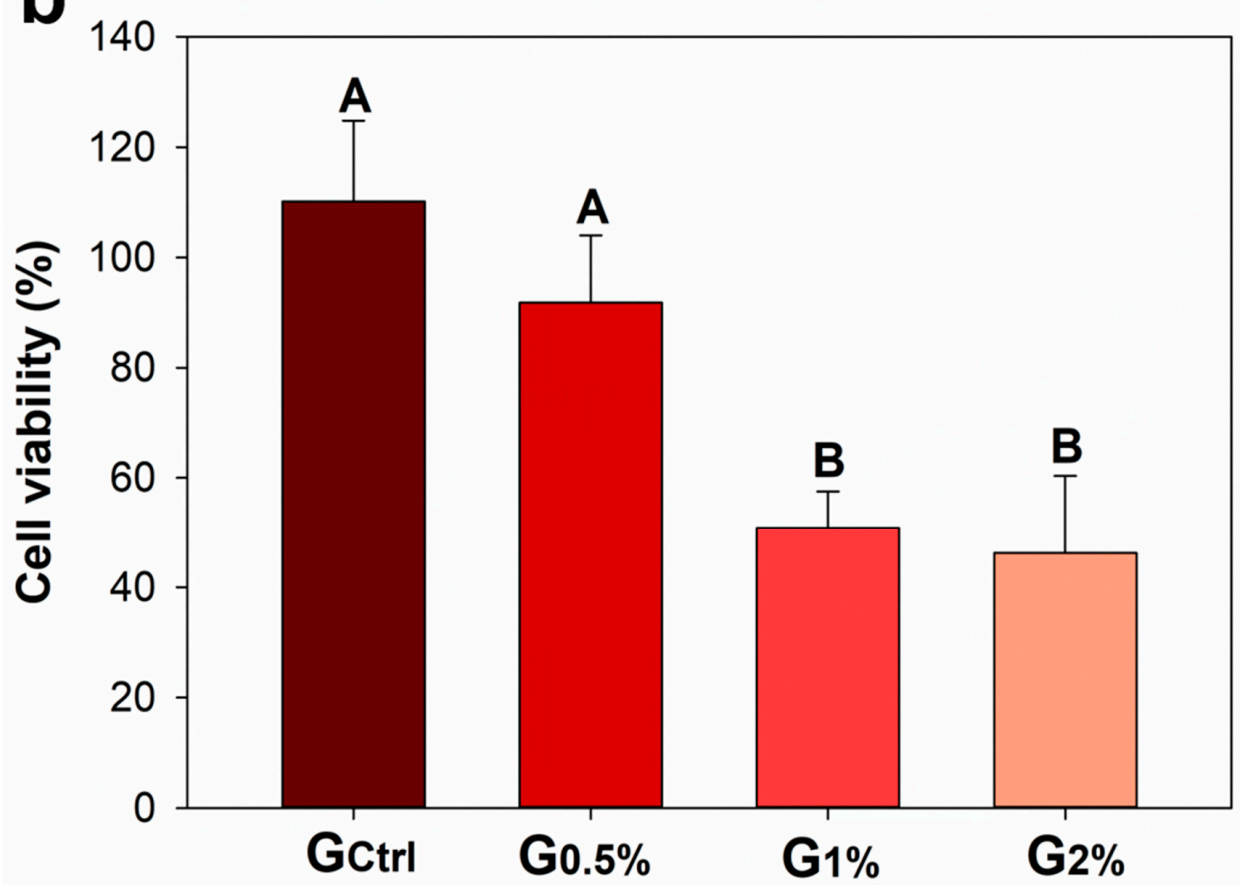

Figure 3. Cytotoxicity evaluation of the experimental dental resins expressed by percentage of cell viability: (a) structure of myristyltrimethylammonium bromide (MYTAB) and schematic drawing of sulforhodamine B (SRB) assay; and (b) MYTAB cytotoxicity assessed in normal human keratinocytes $(\mathrm{HaCaT})$ line. Different capital letters indicate statistical differences among groups $(p<0.05)$. 


\section{Discussion}

Dental resins are reliable materials to restore teeth, and, when used as pit and fissure sealants, could prevent new caries lesions $[18,28,29]$. Nevertheless, the formation of caries lesions around dental resins is still a major concern due to biofilm accumulation [22,30]. In order to prevent this issue, we investigated the effect of a cationic organic compound, MYTAB, in the properties of an experimental dental resin. The formulated resin is a suitable material for dental restorative purposes.

The longevity of dental restorative materials is strongly related to material rates of polymerization. High monomer conversion is essential for polymers to achieve reliable properties and stability [31]. The study of their polymerization behavior of modified formulations assists in understanding the effects of the incorporation of the compound on the functional aspect of the restorative material. Here, the formulated experimental dental resins showed different polymerization kinetics depending on the concentration of MYTAB. The effects were more evident with the addition of $1 \mathrm{wt} \%$ of MYTAB in the resin (Figure $2 \mathrm{~A}-\mathrm{C}$ ). From this concentration, the polymerization process was delayed, and the groups reached the maximum polymerization rate later compared to $\mathrm{G}_{\mathrm{Ctrl}}$ and $\mathrm{G}_{0.5 \%}$.

On the other hand, $\mathrm{G}_{0.5 \%}$ showed a higher maximum polymerization rate compared to all groups (Figure $2 \mathrm{~B}$ ). The rationale for this may be attributed to different viscosities among groups [32]. It was previously suggested that cationic surfactants could increase monomer chain mobility and modify polymerization behavior [33]. The lower viscosity and the higher monomer chain mobility for $\mathrm{G}_{0.5 \%}$ may lead to a higher maximum polymerization rate. Nevertheless, by increasing MYTAB incorporation, the spaces among monomer chains would be increased further, leading to a lower polymerization rate for $\mathrm{G}_{1 \%}$ and $\mathrm{G}_{2} \%$. Despite these events, there was no difference in the degree of conversion among groups, and they achieved high values of conversion, similar to commercial dental resins [34].

Even though all groups presented a reliable degree of conversion, the delay during the polymerization kinetics observed for $\mathrm{G}_{1 \%}$ and $\mathrm{G}_{2} \%$ could induce the formation of a more linear polymer, with lower crosslinking density [35]. Therefore, the mechanical evaluation of the formulated materials was essential in better understanding their performance. The specimens of dental resins were submitted to tensile strength until fracture in a universal testing machine with no statistical difference among groups. The UTS was a promising outcome because the incorporation of antibacterial agents could lead to lower mechanical properties [36]. The dental resins formulated in this study may be used in occlusal surfaces, where repetitive chewing stress is applied. The maintenance of resins' mechanical properties besides the antibacterial activity presented is essential in keeping the material in function.

In chewing sites, the experimental material proposed could be used not only for the prevention of caries lesions [18] but also to treat teeth already affected by the disease [29]. Pits and fissures are sites of difficult hygiene, favoring biofilm accumulation. Dental sealants successfully inhibit dental caries due to their ability to seal the demineralized tissue and form a mechanical barrier, inhibiting bacterial growth, hampering lesion progression, or preventing the demineralization of the sealed area $[18,37]$. The use of dental sealants in children and adolescents decreases the susceptibility to caries development in occlusal surfaces of permanent molars in comparison to people with no sealed teeth. Even among the people with sealed teeth, there are around $18 \%$ who present new lesions over time [18]. The composition of the sealants available in the market does not present antibacterial agents in their composition, which could be a strategy to reduce this percentage.

The parental composite resin formulated had its viscosity manually accessed for friendly use in clinical settings as a sealant. In the previous study with similar QAC, a high antibacterial effect of myristyltrimethylammonium bromide against Enterococcus faecalis was observed [27]. In both cases, these QACs have a long alkyl chain, which increases the QAC's hydrophobicity [38]. Consequently, when leached, these agents are more prone to penetrate bacterial walls and membranes [39]. With MYTAB, the higher its concentration in the dental resin, the lower the viability of S. mutans in biofilm and in planktonic stages.

For the assessment of antibacterial property, discs of the polymerized dental resins entered into contact with an enriched broth containing $S$. mutans as previously performed [13,33,40-42]. 
This bacterium is Gram-positive, and it is present in intraoral multispecies biofilms [43]. S. mutans group is the main bacteria associated with caries lesion development [44], and they can attach to dental and material surfaces $[1,21]$. The samples were exposed to planktonic as well as biofilm stages. During the contact with a dental resin containing MYTAB, planktonic bacteria reduction is suggested because of the leaching of some MYTAB molecules for the broth. The lack of assessment of the long-term antibacterial effect of the dental resins is a limitation of this study. Besides this, the quantities of MYTAB released over time from the polymerized resin is not known. The knowledge about this event could be valuable in order to understand the long-term behavior of the material and to assist in predicting the in vivo outcomes. However, the main goal of this study was to investigate the potential adverse effects of the addition of this compound into the composite to impart an antibacterial effect.

The cytotoxicity test was performed against human keratinocytes via the SRB method. Through this method, proteins of viable cells are stained, indicating increased viability when higher optical density is achieved [45]. The higher the incorporation of MYTAB, the higher the cytotoxic effect observed. This result corroborates with previous studies, which showed that cationic compounds with long-alkyl chains lead to high cytotoxic effects [46]. The International Organization for Standardization (ISO) recommends that biomaterials must promote up to $70 \%$ of cells' viability in order to not be considered cytotoxic [47]. It is worth mentioning that, despite the lower values of viability found for 1 and $2 \mathrm{wt} \%$ of MYTAB, all groups were directly treated with the eluates from the samples. In other words, we did not dilute the agent as other studies do [46], but we did somewhat increase the challenge by using the eluates on human cells during $72 \mathrm{~h}$ of contact.

A similar compound to MYTAB, a quaternary ammounium compound called ATAB, has been found to show antibacterial activity against Enterococcus faecalis, a relevant bacterium to endodontic infections [48]. The main difference between MYTAB and ATAB is the presence of mixing of QACs with different aliphatic chain lengths for ATAB, which does not occur in the case of MYTAB. In the previous study, ATAB was associated with halloysite nanotubes (HNT) that were incorporated in the sealer without the evaluation of ATAB alone [27], which might have repercussions for physical, chemical, or biological properties. In the same study, there were no cytotoxic effects for pulp cells with the incorporation of $10 \mathrm{wt} \%$ of $\mathrm{ATAB} /$ halloysite nanotubes in the sealer, even when the proportion of $\mathrm{ATAB} /$ halloysite nanotubes was 2:1 [27]. Here, MYTAB was not carried out by another system because we aimed to evaluate the QAC itself as a free drug, which may have increased the biological effects. $\mathrm{G}_{0.5 \%}$ showed no cytotoxicity in comparison to $\mathrm{G}_{\mathrm{Ctrl}}$, and both promoted viability higher than $70 \%$. Therefore, the addition of $0.5 \mathrm{wt} \%$ of MYTAB may be a promising method for providing antibacterial activity for a dental resin without compromising its physical, chemical, and biological properties. The material here formulated is an exciting approach to be further translated for clinical trials.

\section{Materials and Methods}

\subsection{Study Design and Formulation of Dental Resins}

The study design is described in the flowchart presented in Figure 4. All reagents of the analytical grade for in vitro experiments were purchased from Sigma-Aldrich (Sigma-Aldrich Chemical Company, St. Louis, MO, USA) if not otherwise specified. First, a parental resin was formulated with two dimethacrylate monomers: bisphenol A glycol dimethacrylates (BisGMA) and triethylene glycol dimethacrylate (TEGDMA), at the proportion of 1:1. As a photoinitiator/co-initiator system, camphorquinone and ethyl 4-dimethylaminobenzoate were added to the resin at $1 \mathrm{~mol} \%$ each. Butylated hydroxytoluene was added at $0.01 \mathrm{wt} \%$ as a polymerization inhibitor. Calcium tungstate $\left(\mathrm{CaWO}_{4}\right)$ was added as inorganic filler at $30 \mathrm{wt} \%$. Colloidal silicon dioxide $\left(\mathrm{SiO}_{2} ;\right.$ Aerosil 200, Evonik, Essen, Germany) was incorporated at $0.7 \mathrm{wt} \%$ to adjust the resin's viscosity. After being hand-mixed for $5 \mathrm{~min}$, they were sonicated for $180 \mathrm{~s}$ and hand-mixed for $5 \mathrm{~min}$.

MYTAB with a purity of $>99 \%$ was added to the parental dental resin formulation at an increased double concentration of $0.5,1$, and $2 \% \mathrm{wt} \%$ mass fractions. 


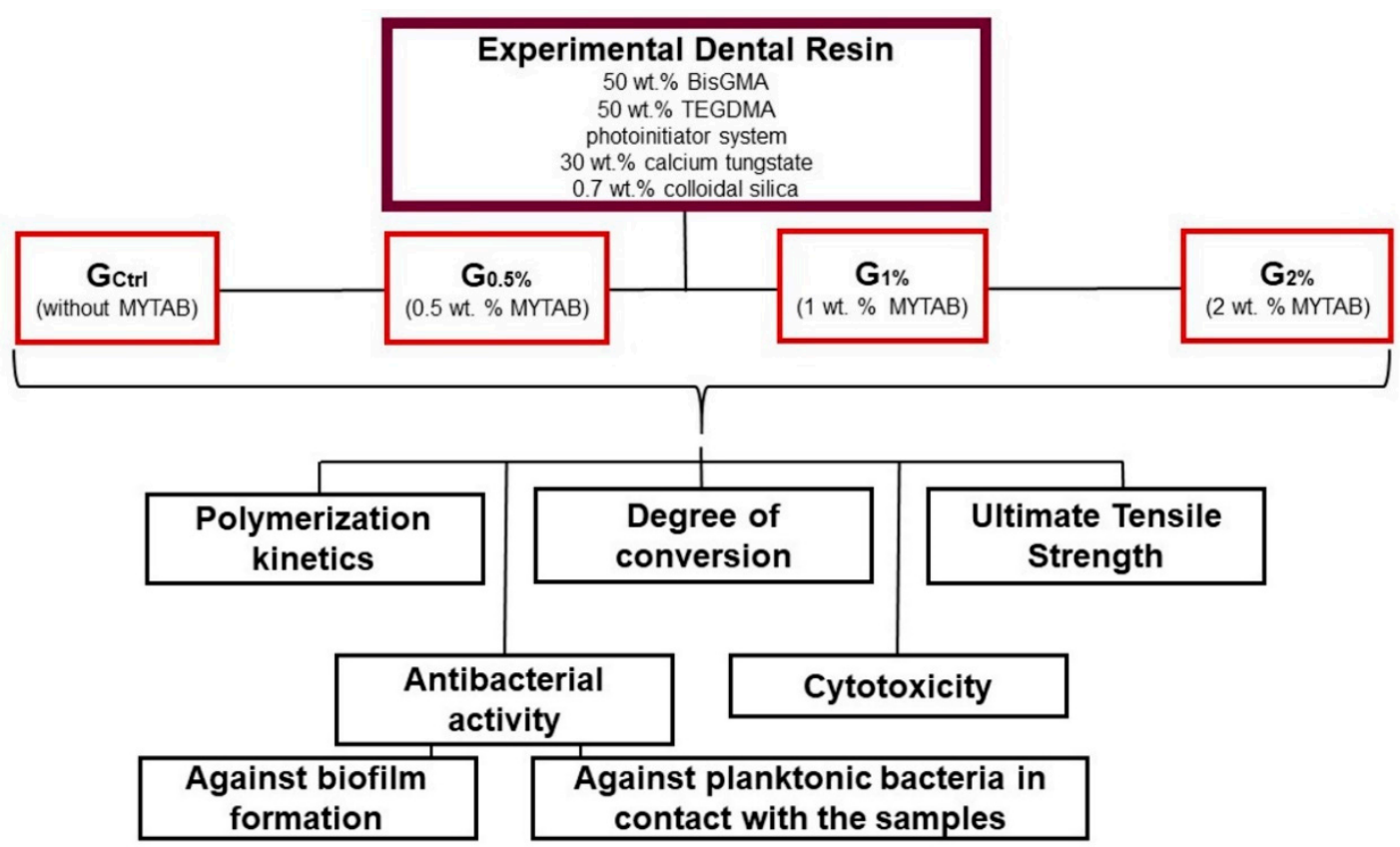

Figure 4. Flowchart of the study design. Experimental dental resins were formulated with different concentrations of a quaternary ammonium compound (MYTAB). Bisphenol A glycol dimethacrylates (BisGMA) and triethylene glycol dimethacrylate (TEGDMA) were used for the monomeric blend. The four experimental groups were evaluated for chemical, physical, and antibacterial properties, alongside their effect against human keratinocytes.

\subsection{Polymerization Kinetics and Degree of Conversion}

Fourier transform infrared spectroscopy (FTIR, Vertex 70, Bruker Optics, Ettinger, Germany) was used to evaluate the polymerization kinetics and the degree of conversion of the experimental dental resin. For this test, three samples per group were analyzed by dispensing them on the attenuated total reflectance (ATR) device in the polyvinylsiloxane matrix measuring $1 \mathrm{~mm}$ thickness and $4 \mathrm{~mm}$ in diameter. To perform the photoactivation of each sample, the light-cured unit (Radii Cal, SDI, Australia; $1200 \mathrm{~mW} / \mathrm{cm}^{2}$ ) was fixed using support to maintain $1 \mathrm{~mm}$ between the tip of the light-cured unit and the top of each sample. During the $40 \mathrm{~s}$ of photoactivation, two spectra were obtained per second in absorbance mode (10 kHz velocity, $4 \mathrm{~cm}^{-1}$ resolution; Opus 6.5 software, Bruker Optics, Ettlingen, Germany) in the range of 4000 to $400 \mathrm{~cm}^{-1}$. The first spectrum obtained was used as "uncured resin dental resin", and the last spectrum as "cured resin dental resin" in the calculation of the degree of conversion. The peak at $1610 \mathrm{~cm}^{-1}$ from aromatic carbon-carbon double bond was used as an internal standard, and the peak at $1640 \mathrm{~cm}^{-1}$ was used as an aliphatic carbon-carbon double bond to calculate the conversion in percentage (Equation (1)) [31]. The polymerization rate was calculated using the degree of conversion at time $t$ subtracted from the degree of conversion at time $t-1$.

Equation (1):

$$
\begin{aligned}
& \text { DC }(\%) \\
& =100 \times\left(\frac{\text { peak height of cured aliphatic } C=C / \text { peak height of cured aromatic } C=C}{\text { peak height of uncured aliphatic } C=C / \text { peak height of uncured aromatic } C=C}\right)
\end{aligned}
$$

\subsection{Ultimate Tensile Strength (UTS)}

Ten samples per group with hourglass shape were prepared in a metallic matrix that was $8.0 \mathrm{~mm}$ long, $2.0 \mathrm{~mm}$ wide, and of $1.0 \mathrm{~mm}$ thickness, with a cross-sectional area of $\pm 1 \mathrm{~mm}^{2}$. Each uncured sample was placed in the mold and photoactivated for $20 \mathrm{~s}$ on each side (bottom and top). The prepared samples were stored in distilled water at $37^{\circ} \mathrm{C}$ for $24 \mathrm{~h}$. The samples were fixed in jigs with cyanoacrylate resin, and they were submitted under tensile strength in a universal testing machine (EZ-SX Series, 
Shimadzu, Kyoto, Japan) at $1 \mathrm{~mm} / \mathrm{min}$ until fracture. The maximum force value (Newtons, $\mathrm{N}$ ) achieved was divided by the constriction area of each sample, which was measured with a digital caliper (Mitutoyo, Kawasaki, Kanagawa, Japan) to calculate the maximum value of tensile strength (Equation (2)). The results were expressed in megapascals (MPa).

Equation (2):

$$
\text { UTS }(\mathbf{M P a})=\left(\frac{\text { Force }(N)}{\text { Constriction area }\left(\mathrm{mm}^{2}\right)}\right)
$$

\subsection{Antibacterial Activity}

Two in vitro assessments were performed to evaluate the antibacterial activity of the experimental dental resin: (1) planktonic bacteria and (2) against biofilm formation on the polymerized samples. The bacteria used in both tests were $S$. mutans (NCTC 10449). Three samples per group were prepared for the biofilm test, and the other three samples per group were used in the test against planktonic bacteria. S. mutans were prepared according to a previous study [13], and the initial inoculum used for the tests was assessed by serial dilution method and colony counting, which indicated an inoculum at $7.8 \times 10^{7} \mathrm{CFU} / \mathrm{mL}$.

To evaluate the antibacterial activity against biofilm formation, the polymerized samples $(1 \mathrm{~mm}$ thickness and $4 \mathrm{~mm}$ diameter) were fixed on Teflon specimens that were fixed on the cover of a 48 -well plate, and this assembly was sterilized with hydrogen peroxide plasma $\left(58 \%, 48 \mathrm{~min}, 56^{\circ} \mathrm{C}\right)[13,49]$. From the initial inoculum, $100 \mu \mathrm{L}$ was added in each well of a 48 -well plate with $900 \mu \mathrm{L}$ of brain-heart infusion (BHI) broth with $1 \mathrm{wt} \%$ of sucrose. All reagents used in the antibacterial activity analysis were purchased from Aldrich Chemical Company (St. Louis, MO, USA). The sterile set of cover and samples was joined with this 48 -well plate and kept for $24 \mathrm{~h}$ under $37^{\circ} \mathrm{C}$ for biofilm formation on the samples. After this period, each sample was detached from the cover and vortexed for $1 \mathrm{~min}$ in $1 \mathrm{~mL}$ of sterile saline solution. The solution was serial diluted up to $10^{-6} \mathrm{~mL}$ and plated on Petri dishes containing BHI agar to count the colonies and to calculate (Equation 3) the colony-forming units per milliliter $(\mathrm{CFU} / \mathrm{mL})$.

Equation (3):

$$
\mathbf{C F U} / \mathbf{m L}=\left(\frac{\text { Avarage number of colonies } x \text { Dilution factor }}{\text { Volume of culture plate }}\right)
$$

To evaluate the antibacterial activity against planktonic bacteria, the BHI broth that was in contact with the polymerized samples along the $24 \mathrm{~h}$ mentioned above was used. From each well of the 48-well plate, $100 \mu \mathrm{L}$ was collected after the $24 \mathrm{~h}$ of bacteria-sample contact and was inserted into Eppendorf tubes with $900 \mu \mathrm{L}$ of saline solution to be vortexed, diluted until $10^{-6}$, and plated on BHI agar Petri dishes. For this test, an additional group was added as a negative control. The negative control was composed of BHI broth and S. mutans at the same proportion (10\% of initial inoculum of bacteria in each well) without samples' contact. Colonies were visually counted, and the results were also expressed in CFU/mL.

\subsection{Cytotoxicity}

To evaluate the possible cytotoxic effect of the experimental dental resin, human keratinocytes (HaCaT, CLS Cell Lines Service GmbH, Eppelheim, Germany) were used in this test [40]. All reagents used to evaluate the possible cytotoxicity of the dental resins were purchased from Aldrich Chemical Company (St. Louis, MO, USA). The keratinocytes were kept in contact $\left(5 \times 10^{3}\right.$ cells/per well) with $100 \mu \mathrm{L}$ of Dulbecco's modified Eagle's medium (DMEM) in 96 -well plates for $24 \mathrm{~h}$ at $37^{\circ} \mathrm{C}$. On the same day, five samples per group ( $1 \mathrm{~mm}$ thickness and $4 \mathrm{~mm}$ diameter) were placed separately in Eppendorf tubes containing $1 \mathrm{~mL}$ of DMEM and kept for $24 \mathrm{~h}$ at $37^{\circ} \mathrm{C}$. Thus, eluates from possible leaching from the samples were formed. These eluates $(100 \mu \mathrm{L})$ were kept in contact with the keratinocytes in the 
96-well plates for $72 \mathrm{~h}$ at $37^{\circ} \mathrm{C}$. There was one group that was maintained without eluates with $100 \mu \mathrm{L}$ of pure DMEM that was used as a control for the test. In addition to using five samples per group, the eluates were applied in five replications, totalizing 100 wells containing eluates from the samples. After $72 \mathrm{~h}, 50 \mu \mathrm{L}$ of trichloroacetic acid/distilled water solution (50:50) was added in each well and kept at $4{ }^{\circ} \mathrm{C}$ for 1 hour to fix the cells on the bottom. Running water (30 s) was used to wash the 96-well plates six times. The 96-well plates were kept at room temperature until drying.

Sulforhodamine B at $0.4 \%(50 \mu \mathrm{L})$ was added in each well, and the 96 -well plates were kept at room temperature for $30 \mathrm{~min}$. The 96 -well plates were washed four times with acetic acid at $1 \%$ and kept at room temperature until drying. Trizma solution at $10 \mathrm{mM}(100 \mu \mathrm{L})$ was added in each well, and the 96-well plates were incubated for 1 hour at room temperature. The absorbance of plates' wells was analyzed at $560 \mathrm{~nm}$, and the cell viability of the wells that contained eluates was compared to the wells without eluates. The viability of the keratinocytes used was normalized against the viability of cells without contact with eluates (negative control). The results were expressed in percentage using the viability of negative control as $100 \%$.

\subsection{Statistical Analysis}

Data normality was evaluated by the Shapiro-Wilk test. One-way ANOVA and Tukey's post-hoc test was used to compare groups for all tests at a level of 0.05 of significance.

\section{Conclusions}

The present study incorporated a not yet investigated quaternary ammonium MYTAB into a dental resin, which achieved potent antibacterial effects against dental plaque microcosm biofilms for the first time. The results showed that (1) MYTAB at $2 \%$ greatly decreased S. mutans in planktonic and biofilm stages compared to $\mathrm{G}_{\mathrm{Ctrl}}$, (2) higher MYTAB mass fraction rendered the adhesive more strongly antibacterial, (3) MYTAB at $1 \%$ mass fraction greatly reduced the cell viability, and (4) the incorporation of MYTAB at a maximum concentration of $2 \%$ had no detrimental effect on the degree of conversion and ultimate tensile strength. MYTAB-containing dental resin is a promising strategy for dental applications.

Author Contributions: P.A.M.S. contributed to design, data acquisition, and analysis, and drafted the manuscript; I.M.G. contributed to design, data acquisition, and analysis, and drafted the manuscript; J.N. contributed to data acquisition and analysis; F.V. contributed to data acquisition and analysis; V.C.B.L. contributed to design, data analysis, and data interpretation; M.A.M. contributed to data analysis and data interpretation, and drafted the manuscript; F.M.C. contributed to conception, design, data acquisition, analysis, and interpretation, and drafted and critically revised the manuscript. All authors have read and agreed to the published version of the manuscript.

Funding: This research received no external funding.

Acknowledgments: This study was financed in part by the Coordenação de Aperfeiçoamento de Pessoal de Nível Superior-Brasil (CAPES)-Finance Code 001.

Conflicts of Interest: The authors declare no conflict of interest.

\section{References}

1. Lin, N.J. Biofilm over teeth and restorations: What do we need to know? Dent. Mater. 2017, 33, 667-680. [CrossRef] [PubMed]

2. Pandey, V.K.; Srivastava, K.R.; Ajmal, G.; Thakur, V.K.; Gupta, V.K.; Upadhyay, S.N.; Mishra, P.K. Differential Susceptibility of Catheter Biomaterials to Biofilm-Associated Infections and Their Remedy by Drug-Encapsulated Eudragit RL100 Nanoparticles. Int. J. Mol. Sci. 2019, 20, 5110. [CrossRef] [PubMed]

3. Alves, D.; Vaz, A.T.; Grainha, T.; Rodrigues, C.F.; Pereira, M.O. Design of an Antifungal Surface Embedding Liposomal Amphotericin B Through a Mussel Adhesive-Inspired Coating Strategy. Front. Chem. 2019, 7, 431. [CrossRef] [PubMed]

4. Donlan, R.M. Biofilms and device-associated infections. Emerg. Infect. Dis. 2001, 7, 277-281. [CrossRef] 
5. He, Y.; Wan, X.; Xiao, K.; Lin, W.; Li, J.; Li, Z.; Luo, F.; Tan, H.; Li, J.; Fu, Q. Anti-biofilm surfaces from mixed dopamine-modified polymer brushes: Synergistic role of cationic and zwitterionic chains to resist staphyloccocus aureus. Biomater. Sci. 2019, 7, 5369-5382. [CrossRef]

6. Jung, J.; Li, L.; Yeh, C.K.; Ren, X.; Sun, Y. Amphiphilic quaternary ammonium chitosan/sodium alginate multilayer coatings kill fungal cells and inhibit fungal biofilm on dental biomaterials. Mater. Sci. Eng. C 2019, 104, 109961. [CrossRef]

7. Melo, M.A.; Orrego, S.; Weir, M.D.; Xu, H.H.; Arola, D.D. Designing Multiagent Dental Materials for Enhanced Resistance to Biofilm Damage at the Bonded Interface. ACS Appl. Mater. Interfaces 2016, 8, 11779-11787. [CrossRef]

8. Degrazia, F.W.; Genari, B.; Leitune, V.C.B.; Arthur, R.A.; Luxan, S.A.; Samuel, S.M.W.; Collares, F.M.; Sauro, S. Polymerisation, antibacterial and bioactivity properties of experimental orthodontic adhesives containing triclosan-loaded halloysite nanotubes. J. Dent. 2018, 69, 77-82. [CrossRef]

9. Makvandi, P.; Jamaledin, R.; Jabbari, M.; Nikfarjam, N.; Borzacchiello, A. Antibacterial quaternary ammonium compounds in dental materials: A systematic review. Dent. Mater. 2018, 34, 851-867. [CrossRef]

10. Braga, R.R.; Fronza, B.M. The use of bioactive particles and biomimetic analogues for increasing the longevity of resin-dentin interfaces: A literature review. Dent. Mater. J. 2019. [CrossRef]

11. Andre, C.B.; Chan, D.C.; Giannini, M. Antibacterial-containing dental adhesives' effects on oral pathogens and on Streptococcus mutans biofilm: Current perspectives. Am. J. Dent. 2018, 31, 37B-41B. [PubMed]

12. Chi, M.; Qi, M.; A, L.; Wang, P.; Weir, M.D.; Melo, M.A.; Sun, X.; Dong, B.; Li, C.; Wu, J.; et al. Novel Bioactive and Therapeutic Dental Polymeric Materials to Inhibit Periodontal Pathogens and Biofilms. Int. J. Mol. Sci. 2019, 20, 278. [CrossRef] [PubMed]

13. Garcia, I.M.; Souza, V.S.; Hellriegel, C.; Scholten, J.D.; Collares, F.M. Ionic Liquid-Stabilized Titania Quantum Dots Applied in Adhesive Resin. J. Dent. Res. 2019, 98, 682-688. [CrossRef] [PubMed]

14. Schwendicke, F.; Frencken, J.E.; Bjorndal, L.; Maltz, M.; Manton, D.J.; Ricketts, D.; Van Landuyt, K.; Banerjee, A.; Campus, G.; Domejean, S.; et al. Managing Carious Lesions: Consensus Recommendations on Carious Tissue Removal. Adv. Dent. Res. 2016, 28, 58-67. [CrossRef] [PubMed]

15. Lynch, C.D.; Opdam, N.J.; Hickel, R.; Brunton, P.A.; Gurgan, S.; Kakaboura, A.; Shearer, A.C.; Vanherle, G.; Wilson, N.H. Guidance on posterior resin composites: Academy of Operative Dentistry-European Section. J. Dent. 2014, 42, 377-383. [CrossRef]

16. Tyas, M.J.; Anusavice, K.J.; Frencken, J.E.; Mount, G.J. Minimal intervention dentistry-A review. FDI Commission Project 1-97. Int. Dent. J. 2000, 50, 1-12. [CrossRef]

17. Ferracane, J.L. Resin composite-State of the art. Dent. Mater. 2011, 27, 29-38. [CrossRef]

18. Ahovuo-Saloranta, A.; Forss, H.; Walsh, T.; Nordblad, A.; Makela, M.; Worthington, H.V. Pit and fissure sealants for preventing dental decay in permanent teeth. Cochrane Database Syst. Rev. 2017, 7, CD001830. [CrossRef]

19. De Munck, J.; Van Meerbeek, B.; Yoshida, Y.; Inoue, S.; Vargas, M.; Suzuki, K.; Lambrechts, P.; Vanherle, G. Four-year water degradation of total-etch adhesives bonded to dentin. J. Dent. Res. 2003, 82, 136-140. [CrossRef]

20. Frassetto, A.; Breschi, L.; Turco, G.; Marchesi, G.; Di Lenarda, R.; Tay, F.R.; Pashley, D.H.; Cadenaro, M. Mechanisms of degradation of the hybrid layer in adhesive dentistry and therapeutic agents to improve bond durability-A literature review. Dent. Mater. 2016, 32, e41-e53. [CrossRef]

21. Kusuma Yulianto, H.D.; Rinastiti, M.; Cune, M.S.; de Haan-Visser, W.; Atema-Smit, J.; Busscher, H.J.; van der Mei, H.C. Biofilm composition and composite degradation during intra-oral wear. Dent. Mater. 2019, 35, 740-750. [CrossRef] [PubMed]

22. Opdam, N.J.; van de Sande, F.H.; Bronkhorst, E.; Cenci, M.S.; Bottenberg, P.; Pallesen, U.; Gaengler, P.; Lindberg, A.; Huysmans, M.C.; van Dijken, J.W. Longevity of posterior composite restorations: A systematic review and meta-analysis. J. Dent. Res. 2014, 93, 943-949. [CrossRef] [PubMed]

23. Imazato, S.; Ma, S.; Chen, J.H.; Xu, H.H. Therapeutic polymers for dental adhesives: Loading resins with bio-active components. Dent. Mater. 2014, 30, 97-104. [CrossRef] [PubMed]

24. Kenawy, E.-R.; Abdel-Hay, F.I.; El-Shanshoury, A.E.-R.R.; El-Newehy, M.H. Biologically active polymers. V. Synthesis and antimicrobial activity of modified poly(glycidyl methacrylate-co-2-hydroxyethyl methacrylate) derivatives with quaternary ammonium and phosphonium salts. J. Polym. Sci. 2002, 40, 2384-2393. [CrossRef] 
25. Lu, G.; Wu, D.; Fu, R. Studies on the synthesis and antibacterial activities of polymeric quaternary ammonium salts from dimethylaminoethyl methacrylate. React. Funct. Polymer 2007, 67, 355-366. [CrossRef]

26. Quan, A.; McGeachie, A.B.; Keating, D.J.; van Dam, E.M.; Rusak, J.; Chau, N.; Malladi, C.S.; Chen, C.; McCluskey, A.; Cousin, M.A.; et al. Myristyl trimethyl ammonium bromide and octadecyl trimethyl ammonium bromide are surface-active small molecule dynamin inhibitors that block endocytosis mediated by dynamin I or dynamin II. Mol. Pharmacol. 2007, 72, 1425-1439. [CrossRef]

27. Monteiro, J.C.; Garcia, I.M.; Leitune, V.C.B.; Visioli, F.; de Souza Balbinot, G.; Samuel, S.M.W.; Makeeva, I.; Collares, F.M.; Sauro, S. Halloysite nanotubes loaded with alkyl trimethyl ammonium bromide as antibacterial agent for root canal sealers. Dent. Mater. 2019, 35, 789-796. [CrossRef]

28. Pallesen, U.; van Dijken, J.W. A randomized controlled 27 years follow up of three resin composites in Class II restorations. J. Dent. 2015, 43, 1547-1558. [CrossRef]

29. Munoz-Sandoval, C.; Gambetta-Tessini, K.; Giacaman, R.A. Microcavitated (ICDAS 3) carious lesion arrest with resin or glass ionomer sealants in first permanent molars: A randomized controlled trial. J. Dent. 2019, 88, 103163. [CrossRef]

30. Chisini, L.A.; Collares, K.; Cademartori, M.G.; de Oliveira, L.J.C.; Conde, M.C.M.; Demarco, F.F. Restorations in primary teeth: A systematic review on survival and reasons for failures. Int. J. Paediatr. Dent. 2018, 28, 123-139. [CrossRef]

31. Collares, F.M.; Ogliari, F.A.; Zanchi, C.H.; Petzhold, C.L.; Piva, E.; Samuel, S.M. Influence of 2-hydroxyethyl methacrylate concentration on polymer network of adhesive resin. J. Adhes. Dent. 2011, 13, 125-129. [PubMed]

32. Barszczewska-Rybarek, I.M. Characterization of urethane-dimethacrylate derivatives as alternative monomers for the restorative composite matrix. Dent. Mater. 2014, 30, 1336-1344. [CrossRef] [PubMed]

33. Martini Garcia, I.; Jung Ferreira, C.; de Souza, V.S.; Castelo Branco Leitune, V.; Samuel, S.M.W.; de Souza Balbinot, G.; de Souza da Motta, A.; Visioli, F.; Damiani Scholten, J.; Mezzomo Collares, F. Ionic liquid as antibacterial agent for an experimental orthodontic adhesive. Dent. Mater. 2019, 35, 1155-1165. [CrossRef] [PubMed]

34. Borges, B.C.; Bezerra, G.V.; Mesquita Jde, A.; Pereira, M.R.; Aguiar, F.H.; Santos, A.J.; Pinheiro, I.V. Effect of irradiation times on the polymerization depth of contemporary fissure sealants with different opacities. Braz. Oral Res. 2011, 25, 135-142. [CrossRef] [PubMed]

35. Rodrigues, S.B.; Collares, F.M.; Leitune, V.C.; Schneider, L.F.; Ogliari, F.A.; Petzhold, C.L.; Samuel, S.M. Influence of hydroxyethyl acrylamide addition to dental adhesive resin. Dent. Mater. 2015, 31, 1579-1586. [CrossRef]

36. Vidal, M.L.; Rego, G.F.; Viana, G.M.; Cabral, L.M.; Souza, J.P.B.; Silikas, N.; Schneider, L.F.; Cavalcante, L.M. Physical and chemical properties of model composites containing quaternary ammonium methacrylates. Dent. Mater. 2018, 34, 143-151. [CrossRef]

37. Liang, Y.; Deng, Z.; Dai, X.; Tian, J.; Zhao, W. Micro-invasive interventions for managing non-cavitated proximal caries of different depths: A systematic review and meta-analysis. Clin. Oral Investig. 2018, 22, 2675-2684. [CrossRef]

38. Yoshimura, T.; Chiba, N.; Matsuoka, K. Supra-long chain surfactants with double or triple quaternary ammonium headgroups. J. Colloid Interface Sci. 2012, 374, 157-163. [CrossRef]

39. Wang, Y.; Costin, S.; Zhang, J.F.; Liao, S.; Wen, Z.T.; Lallier, T.; Yu, Q.; Xu, X. Synthesis, antibacterial activity, and biocompatibility of new antibacterial dental monomers. Am. J. Dent. 2018, 31, 17b-23b.

40. Garcia, I.M.; Rodrigues, S.B.; de Souza Balbinot, G.; Visioli, F.; Leitune, V.C.B.; Collares, F.M. Quaternary ammonium compound as antimicrobial agent in resin-based sealants. Clin. Oral Investig. 2019. [CrossRef]

41. Garcia, I.M.; Rodrigues, S.B.; Leitune, V.C.B.; Collares, F.M. Antibacterial, chemical and physical properties of sealants with polyhexamethylene guanidine hydrochloride. Braz. Oral Res. 2019, 33, e019. [CrossRef] [PubMed]

42. Machado, A.H.S.; Garcia, I.M.; Motta, A.S.D.; Leitune, V.C.B.; Collares, F.M. Triclosan-loaded chitosan as antibacterial agent for adhesive resin. J. Dent. 2019, 83, 33-39. [CrossRef] [PubMed]

43. Metwalli, K.H.; Khan, S.A.; Krom, B.P.; Jabra-Rizk, M.A. Streptococcus mutans, Candida albicans, and the human mouth: A sticky situation. PLoS Pathog. 2013, 9, e1003616. [CrossRef] [PubMed] 
44. Kirstila, V.; Hakkinen, P.; Jentsch, H.; Vilja, P.; Tenovuo, J. Longitudinal analysis of the association of human salivary antimicrobial agents with caries increment and cariogenic micro-organisms: A two-year cohort study. J. Dent. Res. 1998, 77, 73-80. [CrossRef]

45. van Tonder, A.; Joubert, A.M.; Cromarty, A.D. Limitations of the 3-(4,5-dimethylthiazol-2-yl)-2,5-diphenyl2H-tetrazolium bromide (MTT) assay when compared to three commonly used cell enumeration assays. BMC Res. Notes 2015, 8, 47. [CrossRef]

46. Gindri, I.M.; Siddiqui, D.A.; Bhardwaj, P.; Rodriguez, L.C.; Palmer, K.L.; Frizzo, C.P.; Martins, M.A.P.; Rodrigues, D.C. Dicationic imidazolium-based ionic liquids: A new strategy for non-toxic and antimicrobial materials. RSC Adv. 2014, 4, 62594-62602. [CrossRef]

47. International Organization for Standardization (ISO). Biological Evaluation of Medical Devices_Part 5: Tests for in vitro Cytotoxicity; ISO 10993-5:2009(E); ISO: Vernier, Geneva, Switzerland, 2009; Volume 1, p. 34.

48. Stuart, C.H.; Schwartz, S.A.; Beeson, T.J.; Owatz, C.B. Enterococcus faecalis: Its role in root canal treatment failure and current concepts in retreatment. J. Endod. 2006, 32, 93-98. [CrossRef]

49. Genari, B.; Leitune, V.C.B.; Jornada, D.S.; Camassola, M.; Arthur, R.A.; Pohlmann, A.R.; Guterres, S.S.; Collares, F.M.; Samuel, S.M.W. Antimicrobial effect and physicochemical properties of an adhesive system containing nanocapsules. Dent. Mater. 2017, 33, 735-742. [CrossRef]

(C) 2020 by the authors. Licensee MDPI, Basel, Switzerland. This article is an open access article distributed under the terms and conditions of the Creative Commons Attribution (CC BY) license (http://creativecommons.org/licenses/by/4.0/). 